\title{
Proinflammatory monocyte polarization in type 2 diabetes mellitus and coronary heart disease
}

\author{
Nikita G. Nikiforov ${ }^{1,2,3}, K_{\text {Karina O. Galstyan }}^{4}$, Liudmila V. Nedosugova ${ }^{4}$, Natalia V. Elizova ${ }^{1}$, Kira I. Kolmychkova $^{4}$, \\ Ekaterina A. Ivanova ${ }^{5}$ \\ ${ }^{1}$ Institute of General Pathology and Pathophysiology, 125315 Moscow, Russia. \\ ${ }^{2}$ Institute of Clinical Cardiology, Russian Cardiology Research and Production Complex, Ministry of Healthcare, 121552 Moscow, Russia. \\ ${ }^{3}$ Institute for Atherosclerosis Research, Skolkovo Innovation Center, 121609 Moscow, Russia. \\ ${ }^{4}$ Sechenov's First Moscow State Medical University, 119992 Moscow, Russia. \\ ${ }^{5}$ Department of Development and Regeneration, KU Leuven, 3000 Leuven, Belgium.
}

Correspondence to: Dr. Ekaterina A. Ivanova, Department of Development and Regeneration, KU Leuven, 3000 Leuven, Belgium.

E-mail: kate.ivanov@gmail.com

How to cite this article: Nikiforov NG, Galstyan KO, Nedosugova LV, Elizova NV, Kolmychkova KI, Ivanova EA. Proinflammatory monocyte polarization in type 2 diabetes mellitus and coronary heart disease. Vessel Plus 2017;1:192-5.

Article history:

Received: 10 Jun 2017

Accepted: 20 Sep 2017

Published: 28 Dec 2017

Key words:

Type 2 diabetes mellitus,

coronary heart disease,

M1/M2 monocyte polarization,

oxidative stress,

atherosclerosis,

inflammatory

\begin{abstract}
Aim: Type 2 diabetes mellitus (T2DM) is associated with rapid progression of atherosclerosis. There is no doubt that inflammation is involved in atherogenesis. Recent studies showed the relationship between the development of atherosclerotic plaque formation and the amount of pro-inflammatory (M1) activated macrophages in situ. Methods: The authors studied the ability of circulating monocytes isolated from patients with diabetes $(n=28)$, coronary heart disease (CHD) $(n=27)$ and healthy subjects $(n=50)$ to be activated into M1 phenotype in vitro. Results: Increased levels of basal and stimulated secretion of tumor necrosis factor alpha (TNF- $\alpha$ ) was observed in diabetic patients compared with healthy subjects. On the contrary, in patients with CHD, decreased secretion of the pro-inflammatory cytokine, TNF- $\alpha$, was found. A direct correlation between glycated hemoglobin (HbAlc) levels in T2DM patients and basal secretion of TNF- $\alpha$ from monocytes was observed. Conclusion: The authors found diametrically different responses of monocytes from T2DM and CHD under pro-inflammatory stimuli.
\end{abstract}

\section{INTRODUCTION}

Increased prevalence of type 2 diabetes mellitus (T2DM) around the globe has been deemed a "noninfectious epidemic" and according to the International Diabetes Federation, it is predicted that the number of patients with T2DM will reach 642 million people by $2040^{[1]}$.
T2DM patients are more likely to exhibit an accelerated development of atherosclerosis and have a 3-4fold increased risk for cardiovascular mortality ${ }^{[2]}$. Hyperglycemia is currently considered the main culprit for vascular lesion progression. A meta-analysis of 20 different studies involving 95,783 patients, followed for 12 years, led to the conclusion that glucose is the common underlying risk factor for atherosclerosis,

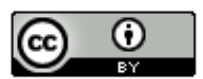

This is an open access article licensed under the terms of Creative Commons Attribution 4.0 International License (https://creativecommons.org/licenses/by/4.0/), which permits unrestricted use, distribution, and reproduction in any medium, as long as the original author is credited and the new creations are licensed under the identical terms.

For reprints contact: service@oaepublish.com

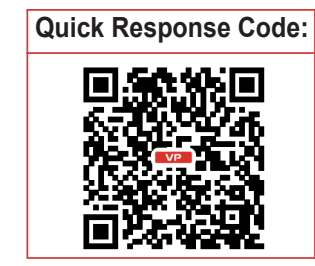


acute cardiovascular mortality and elevations in circulating cholesterol and blood pressure ${ }^{[3]}$. It is likely that this phenomenon arises from excessive formation of reactive oxygen species in mitochondria due to oxidation of glucose under hyperglycemic blood conditions ${ }^{[4,5]}$. We have previously observed a 10-25-fold increase in the oxidative modification of lipoproteins in patients with T2DM, compared to healthy subjects ${ }^{[6]}$. Macrophages capturing modified low density lipoproteins (LDL) through scavengerreceptors accumulate lipids and become lipid-rich foam cells, thereby leading to atherogenesis ${ }^{[7]}$.

Signs of local and systemic non-specific inflammatory processes in atherosclerosis trace to the earliest stages of vascular lesion development ${ }^{[8]}$. Increased oxidation of LDL contributes to their diffusion into the subendothelial space and activation of nuclear factor kappa-B (NF-kB) through interaction with toll-like receptors. This process leads to production of inflammatatory mediators ${ }^{[9]}$. However, activation of NF-kB also activates genetic programs necessary for resolution of inflammation ${ }^{[10]}$. Recent studies showed the relationship between the progression of atherosclerotic plaque formation and the ratio of pro-inflammatory (M1) and anti-inflammatory (M2) activated macrophages ${ }^{[11]}$. The role of polarization of macrophages in T2DM is still unclear. To address this, we studied the basal and induced secretion of the pro-inflammatory cytokine, tumor necrosis factor alpha (TNF- $\alpha$ ), by monocytes isolated from the blood of patients with newly diagnosed T2DM, compared to those of patients with coronary heart disease.

\section{METHODS}

Primary cultures of human monocytes were obtained from peripheral blood of 28 non-treated patients with newly diagnosed diabetes 2 (11 men, 17 women) and 27 patients (20 men, 7 women) with coronary heart disease (CHD) without disturbances in carbohydrate metabolism. As a control group, 50 healthy volunteers without disturbances in carbohydrate and lipid metabolism were examined ( 25 men, 25 women) [Table 1].

The levels of glucose in the blood serum were determined by hexokinase (Thermo Scientific). The levels of glycated hemoglobin in red blood cells were determined by the instrument immune inhibition Bekman Coulter AU 680.

None of the patients had any clinical symptoms of systemic inflammation. The study was approved by the local ethics committee and was carried out in agreement with the Declaration of Helsinki. Written informed consent was obtained from all patients.

In order to evaluate the ability of monocytes to be activated, cells were isolated from whole blood using magnetic CD14-positive separation with MACS CD14positive microbeads (MiltenyiBiotec) and MACS separation columns (MiltenyiBiotec). Monocytes were seeded into sterile 24-well culture plates at a density of $10^{6}$ cells per well with X-Vivo serum-free medium (Lonza) and cultured at $37{ }^{\circ} \mathrm{C}$ in $\mathrm{CO}_{2}$-incubator $(95 \%$ air and $5 \% \mathrm{CO}_{2}$ ).

Once cultured, monocytes were stimulated with $100 \mathrm{ng} / \mathrm{mL}$ of interferon-y. Secretion of TNF- $\alpha$ was considered a marker of the pro-inflammatory response. The concentration of TNF- $\alpha$ in the culture medium was determined by enzyme-linked immunosorbent assay (ELISA) on day 1 after cell isolation.

Statistical processing was performed using the SPSS package (SPSS Inc., USA). T-test was used to compare between groups.

\section{RESULTS}

As a model for investigation of changes in the immune system of studied patients, we used primary culture of monocytes isolated from the blood and evaluated cellular responses to pro-inflammatory stimuli. We revealed possible bias of monocyte polarization towards the M1 phenotype. This procedure was applied to non-treated T2DH patients $(n=28), \mathrm{CHD}$ patients $(n=27)$ and healthy subjects $(n=50)$ (their clinical characteristics are given in Table 1). Cells were stimulated with interferon- $\gamma(100 \mathrm{ng} / \mathrm{mL})$. Secretion of TNF- $\alpha$ was measured by ELISA.

Monocytes from subjects with $\mathrm{CHD}$ were characterized by a low degree of basal secretion of TNF- $\alpha$ [Table 2]. Moreover, monocytes lacked the ability to be activated in response to both pro- and anti-inflammatory stimuli. On the contrary, monocytes from subjects with T2DM exhibited a significant 3 -fold increase in the basal secretion of TNF- $\alpha$ as well as a 3-4-fold increase in the production of TNF- $\alpha$ in response to stimuli.

In this study, we attempted to explore the relationship between glycated hemoglobin (HbA1c) levels in patients with T2DM and susceptibility of their monocytes to activation. The obtained data indicated that there was an obvious trend towards a direct association between $\mathrm{HbA1c}$ levels and the monocyte basal secretion of TNF- $\alpha$ [Figure 1]. 
Table 1: Clinical characteristics of studied groups of patients

\begin{tabular}{lccc}
\hline & $\begin{array}{c}\text { Healthy } \\
\text { subjects } \\
(\boldsymbol{n}=\mathbf{5 0})\end{array}$ & $\begin{array}{c}\text { T2DM } \\
\text { patients } \\
(\boldsymbol{n}=\mathbf{2 8})\end{array}$ & $\begin{array}{c}\text { CHD } \\
\text { patients } \\
(\boldsymbol{n}=\mathbf{2 7})\end{array}$ \\
\hline $\begin{array}{l}\text { Age (years) } \\
\begin{array}{l}\text { Gender } \\
\text { (male/female) }\end{array}\end{array}$ & $60(9)$ & $62(12)$ & $67(7)$ \\
$\begin{array}{l}\text { HbA1c (\%) } \\
\text { Body mass } \\
\text { index (kg/m })\end{array}$ & $5.2(0.3)$ & $11 / 17$ & $20 / 7$ \\
$\begin{array}{l}\text { Cholesterol } \\
(\text { mmol/L) }\end{array}$ & $27.5(2.2)$ & $32.1(4.3)^{*}$ & $28.2(5.01)$ \\
$\begin{array}{l}\text { Triglicerides } \\
(\mathrm{mmol} / \mathrm{L})\end{array}$ & $0.94(0.5)$ & $5.0(1.2)$ & $5.6(1.0)^{*}$ \\
\hline
\end{tabular}

Values listed are means (standard deviation). *Significant difference from healthy subjects, $P<0.05$. T2DM: type 2 diabetes mellitus; CHD: coronary heart disease

Table 2: Proinflammatory activation of monocytes from T2DM and CHD patients

\begin{tabular}{lcc}
\hline & \multicolumn{2}{c}{ TNF- $\alpha(\mathrm{pg} / \mathrm{mL})$} \\
\cline { 2 - 3 } & Basal & Stimulated \\
\hline Healthy subjects $(n=50)$ & $270 \pm 75$ & $378 \pm 92$ \\
T2DM patients $(n=28)$ & $750 \pm 92^{*}$ & $1,571 \pm 111^{*}$ \\
CHD patients $(n=27)$ & $151 \pm 70^{*, \#}$ & $139 \pm 51^{*, \#}$ \\
\hline
\end{tabular}

*Significant difference from healthy subjects, $P<0.05$; \#significant difference from T2DM patients, $P<0.05$. T2DM: type 2 diabetes mellitus; CHD: coronary heart disease

\section{DISCUSSION}

Diabetes mellitus is associated with a rapid development of atherosclerosis. Previously it was demonstrated that oxidative stress under hyperglycemic conditions promotes lipid infiltration to the vascular wall caused by increased oxidation of lipoproteins ${ }^{[12]}$.

Furthermore, metabolic syndrome, which encompasses T2DM, is characterized by chronic systemic inflammation. Mechanisms underlying these pathological processes remain unclear ${ }^{[13-15]}$. In response to the development of obesity, adipocytes and endothelial cells reduce their insulin sensitivity, promoting the development of T2DM and cardiovascular complications. In turn, development of hyperglycemia and hyperinsulinemia provoke oxidative stress and cause multiple inflammatory reactions ${ }^{[16]}$.

Polarization of monocytes may reflect the status of the innate immune system. We studied the ability of circulating monocytes from patients with T2DM, CHD and healthy subjects to be activated into $\mathrm{M} 1$ and $\mathrm{M} 2$ phenotypes in vitro. Increased levels of basal and stimulated secretion of the pro-inflammatory cytokine, TNF- $\alpha$, were observed in diabetic patients, compared

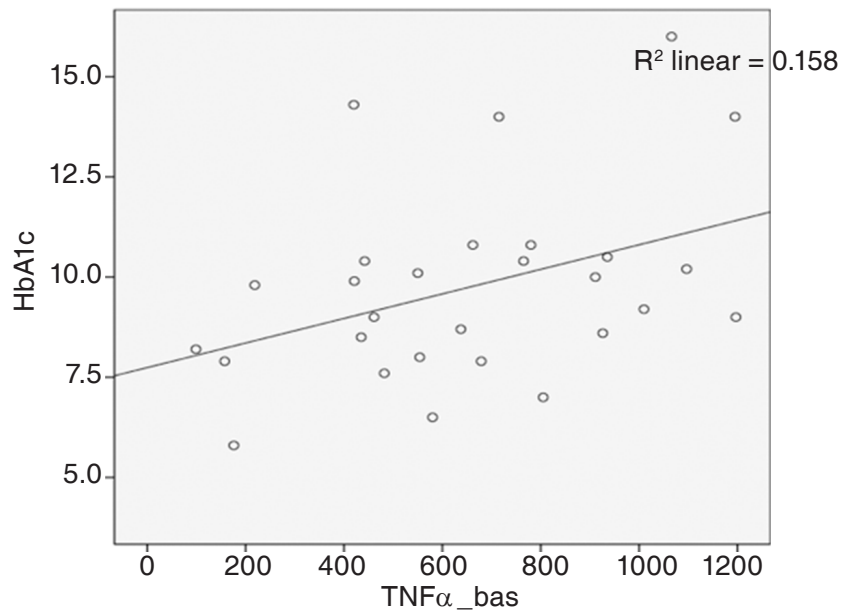

Figure 1: Correlation plot between $\mathrm{HbA1c}$ level and the monocyte basal secretion of TNF- $\alpha$. TNF- $\alpha$ : tumor necrosis factor alpha

to healthy subjects.

Such strong polarization of monocytes caused by pro-inflammatory stimuli may be associated with the activation of many transcription factors, particularly NF$\mathrm{kB}$. Activation of NF-kB in T2DM is associated with hyperglycaenmia-induced mitochondrial superoxide overproduction, leading to the development of oxidative stress $^{[4,17]}$. Abundance of superoxide partially inhibits the glycolytic enzyme, GAPDH, thus diverting upstream metabolites from glycolysis into pathways of glucose over-utilization. This leads to increased flux of dihydroxyacetone phosphate to diacylglycerol, an activator of PKC, and of triose phosphates to methylglyoxal, the main intracellular advanced glycation end (AGE) products precursor. In its turn, protein kinase $C$ is responsible for the activation of NF-kB ${ }^{[17]}$ contributing to improvements in adhesion of monocytes to the vascular wall ${ }^{[17,18]}$. Jin et al. ${ }^{[19]}$ found that AGEs not only predominantly induce macrophages to secrete inflammatory cytokines, but also induce M1 polarization. Moreover, AGEs activate the RAGE/NF-kB pathway, whereas the blockade of RAGE or NF-kB can attenuate macrophage activation ${ }^{[19,20]}$. We also found a direct correlation between the levels of $\mathrm{HbA} 1 \mathrm{c}$ and TNF- $\alpha$ in patients with newly diagnosed diabetes [Figure 1]. This observation may be associated not only with more severe oxidative stress in conditions of hyperglycemia, but also with obesity in patients ${ }^{[21]}$.

On the contrary, monocytes from CHD patients lacked the ability to be activated in response to proinflammatory stimuli. Recently, similar a phenomenon was found in patients with atherosclerosis ${ }^{[22]}$.

In conclusion, this study aimed to establish the cause of atherosclerosis in patients with diabetes in the context 
of chronic inflammation. Unexpectedly, we found diametrically different abilities of monocytes from T2DM and $\mathrm{CHD}$ to respond under pro-inflammatory stimulus.

\section{DECLARATIONS}

\section{Authors' contributions}

Concept and performed experimental studies, general coordination, supervision of the research projectand wrote the manuscript: N.G. Nikiforov

Literature search and patients' recruitment: L.V. Nedosugova

Clinical examination and clinical data acquisition: K.O. Galstyan

Cell culture experiments: N.V. Elizova, K.I. Kolmychkova Manuscript editing: E.A. Ivanova

\section{Financial support and sponsorship}

This work was supported by Russian Science Foundation (Grant \# 14-15-00112).

\section{Conflicts of interest}

There are no conflicts of interest.

\section{Patient consent}

All participants gave their written informed consent prior to their inclusion in the study.

\section{Ethics approval}

It was approved by the local ethics committee of the Institute for Atherosclerosis Research, Skolkovo Innovation Center, Moscow, Russia.

\section{REFERENCES}

1. IDF Diabetes Atlas 7th Edition (2015). Available from: http://www.idf.org/e-library/epidemiology-research/diabetes-atlas.html. [Last accessed on 29 Sep 2017]

2. Kanter JE, Bornfeldt KE. Inflammation and diabetes-accelerated atherosclerosis: myeloid cell mediators. Trends Endocrinol Metab 2013;24:137-44.

3. Coutinho M, Gerstein HC,Wang Y, Yusuf S. The relationship between glucose and incident of cardiovascular events. A meta regression analysis of published data from 20 studies of 93,7883 individuals followed for 12.5 years. Diabetes Care 1999;22:233-40.

4. Brownlee M. Biochemistry and molecular cell biology of diabetic complications. Nature 2001;414:813-20.

5. Evans JL, Goldfine ID, Maddux BA, Grodsky GM. Oxidative stress and stress-activated signaling pathways: a unifying hypothesis of type 2 diabetes. Endocr Rev 2002;23:599-622.

6. Lankin VZ, Lisina MO, Arzamastseva NE, Konovalova GG,
Nedosugova LV, Kaminnyi AI, Tikhaze AK, Ageev FT, Kukharchuk $\mathrm{VV}$, Belenkov YN. Oxidative stress in atherosclerosis and diabetes. Bull Exp Biol Med 2005;140:41-3.

7. Lavi S, McConnell JP, Rihal CS, Prasad A, Mathew V, Lerman LO, Lerman A. Local production of lipoprotein-associated phospholipase A2 and lysophosphatidylcholine in the coronary circulation: association with early coronary atherosclerosis and endothelial dysfunction in humans. Circulation 2007;115:2715-21.

8. Tousoulis D, Davies G, Stefanadis C, Toutouzas P, Ambrose JA. Inflammatory and thrombotic mechanisms in coronary atherosclerosis. Heart 2003;89:993-7.

9. Bonizzi G, Karin M. The two NF-kappaB activation pathways and their role in innate and adaptive immunity. Trends Immunol 2004;25:280-8.

10. Lawrence T, Gilroy DW. Chronic inflammation: a failure of resolution? Int J Exp Pathol 2007;88:85-94.

11. MantovaniA,Sozzani S, Locati M, Allavena P, Sica A. Macrophage polarization: tumor-associated macrophages as a paradigm for polarized M2 mononuclear phagocytes. Trends Immunol 2002;2:54955.

12. Arzamastseva NE, Lankin VZ, Konovalova GG, Tikhaze AK, Ageev FT, Lapina YV, Narusov OY, Mareev VY, Belenkov YN. Oxidative stress in patients with chronic heart failure and type 2 diabetes mellitus. Bull ExpBiol Med 2007;143:207-9.

13. Wellen KE, Hotamisligil GS. Inflammation, stress, and diabetes. J Clin Invest 2005;115:1111-9.

14. Neels JG, Olefsky JM. Inflamed fat: what starts the fire? J Clin Invest 2006;116:33-5.

15. Sobenin IA, Galitsyna EV, Grechko AV, Orekhov AN. Small dense and desialylated low density lipoprotein in diabetic patients. Vessel Plus 2017;1:29-37.

16. Fernandez-Real JM, Ricart W. Insulin resistance and chronic cardiovascular inflammatory syndrome. Endocr Rev 2003;24:278-301.

17. Xia P, Inoguchi T, Kern TS, Engerman RL, Oates PJ, King GL. Characterisation of the mechanism for the chronic activation of diacylglycerol-protein kinase $\mathrm{C}$ in diabetes and hypergalactosaemia. Diabetes 1994;43:1122-9.

18. Ceolotto G, Gallo A, Miola M, Sartori M, Trevisan R, Del Prato S, Semplicini A, Avogaro A. Protein kinase C activity is acutely regulated by plasma glucose concentration in human monocytes in vivo. Diabetes 1999;48:1316-22.

19. Jin X, Yao T, Zhou Z, Zhu J, Zhang S, Hu W, Shen C. Advanced glycation end products enhance macrophages polarization into M1 phenotype through activating RAGE/NF-kB pathway. Bio Med Res Int 2015;2015:732450.

20. Bouhlel MA, Derudas B, Rigamonti E, Dièvart R, Brozek J, Haulon S, Zawadzki C, Jude B, Torpier G, Marx N, Staels B, Chinetti-Gbaguidi G. PPARgamma activation primes human monocytes into alternative M2 macrophages with anti-inflammatory properties. Cell Metab 2007;6:137-43.

21. Kraakman MJ, Murphy AJ, Jandeleit-Dahm K, Kammoun HL. Macrophage polarization in obesity and type 2 diabetes: weighing down our understanding of macrophage function? Front Immunol 2014;470:1-6.

22. Ivanova EA, Orekhov AN. Monocyte activation in immunopathology: cellular test for development of diagnostics and therapy. J Immunol Res 2016;2016:4789279. 